\title{
Synthesis of Polymers from Fatty Alcohol and Acrylic Acid and its Impact on Tribological Properties
}

\author{
Sharmishtha Khalkar, DiptiNarayan Bhowmick and Amit Pratap*
}

Department of Oils, Oleochemicals and Surfactants Technology, Institute of Chemical Technology (University under Section 3 of UGC Act 1956; Formerly UDCT/ UICT), Nathalal Parekh Road, Matunga (East), Mumbai-400 019 INDIA

\begin{abstract}
Anhydride copolymers were synthesized from acrylic acid and fatty alcohols (C12- C18, C18:1). These n-alkyl acrylates were treated with maleic anhydride in presence of hydrogen peroxide in second step, to form anhydride copolymer. The anhydride copolymer further reacted to n-butylamine to form poly (n-acrylate-co-nbutylmalemide). The compounds were used as pour point depressant (PPD) additive. The synthesized experimental pour point depressants were added in different concentrations to conventional base stock $(150 \mathrm{~N}$ and $500 \mathrm{~N})$, which had no other additive content before. Synthesized additives were effective as viscosity index improver but also lowered the pour point. These results were comparable with industrial product. Furthermore all additives showed antiwear (AW) and extreme pressure (EP) properties. The resultant anhydride copolymer can act as multifunctional additive, which is novelty of the work.
\end{abstract}

Key words: Tribological properties, viscosity index improver, pour point depressant, wear scar, weld load, coefficient of friction

\section{Introduction}

For diesel fuels (especially in winter) the pour point depressant additive is one of the most important components of additives or additive packages. Generally, the pour point additives are able to decrease the cloud point and cold filter plugging. The n-acrylate polymer based additives are widely used as pour point depressants in the oil industry ${ }^{1}$.

The pour point of the crude oil is the temperature at which the crude is just capable to flow under specified condition of testing. Crude oil containing high amount of wax exhibit high pour point. Pour point depressants (PPD) co crystallise with wax that interferes the crystal network to reduces wax crystal size and thereby lower the pour point ${ }^{7,8)}$. Instead of the needle-like paraffin crystals which rapidly cause paraffin gelation, densely packed, round crystals are formed which hardly affect flowing properties even at temperatures below the pour point. The corresponding pour point depressants (PPDs) are in principle, comb-like and contain C12-C18 paraffinic side chains. By determining the polymer solubility and crystallization of paraffinic components in the base oil, the optimum PPD-mix and concentration can be determined for every base oil mixture.

Crude oil contains a wide range of hydrocarbon components with extremely differing physical properties. The crystalline lattice structure of wax gels with and without
PPD had been studied by Srivastava et al. using $X R D^{2)}$. It was suggested that paraffin crystallized with a predominantly orthorhombic structure in isolated petroleum waxes. When forming gels in solvents, the lattice structure of wax changed to the hexagonal form. The pour point depressant additive hastened the development of hexagonal planes, the additive molecules seemed to provide the necessary energy to paraffin molecules to crystallize in this high energy form. The similar phenomenon was found by Zhang fusheng when he studied the interactions between wax and PPD using the infrared spectrometric ${ }^{3)}$.

In general, inhibition of fatty compound, crystallization has been considered to occur in the presence of PPD by nucleation, co-crystallization or adsorption. It is generally believed that the PPD function by disrupting or preventing the formation of three-dimensional wax networks, leaving the amount of crystalline wax unaffected. However, based on the study of Srivastava and Zhang fusheng as well as the relation between the wax crystal structure and its thermodynamic properties, it can be concluded that the PPD can have an effect on the amount of crystallized compound. Pour point is widely used to evaluate the low temperature flowability of crude oil ${ }^{4)}$.

The kinematic viscosity of a fluid is dependent on the external parameters of pressure and temperature. A great

\footnotetext{
*Correspondence to: Amit Pratap, Department of Oils, Oleochemicals and Surfactants Technology, Institute of Chemical Technology (University under Section 3 of UGC Act 1956; Formerly UDCT/ UICT), Nathalal Parekh Road, Matunga (East), Mumbai-400 019 INDIA E-mail: amitpratap0101@ rediffmail.com, ap.pratap@ictmumbai.edu.in Accepted October 12, 2012 (recieved for review May 29, 2012) Journal of Oleo Science ISSN 1345-8957 print / ISSN 1347-3352 online http://www.jstage.jst.go.jp/browse/jos/ http://mc.manusriptcentral.com/jjocs
} 
number of applications specify viscosity at a defined temperature, in the case of hydraulic equipment at $40^{\circ} \mathrm{C}$ and $100^{\circ} \mathrm{C}$, to achieve optimum pump efficiency. The base oil solubility of these polymer chains deteriorates as the temperature falls and improves with increasing temperature so that an increase in viscosity induced by viscosity modifiers also increases the viscosity index ${ }^{5)}$.

The operation of machines and industrial gears under severe conditions necessitated the development of lubricants that were operated at high temperatures and pressures. Due to excessive increases in temperature under extreme conditions, the boundary film of the fluid lubricant collapses leading to adhesion and surface damage of sliding metallic surfaces. Under such conditions, the friction and surface damage can be minimized by the use of certain extreme pressure (EP) and antiwear (AW) additives ${ }^{6)}$.

A1, A2, A3, A4 and A5 were the Poly (n-acrylate-co-nbutylmaleimide) additives synthesized with individual fatty alcohols (C12-C18 and C18:1). Fatty alcohols were obtained as a gift sample from M/s Godrej Industries Ltd., Mumbai (Refer section 2.1) Industrial sample was referred as K-26 was the reference sample received from M/s Kusha Chemicals, Mumbai. Novelty of this work was to use p-TSA as a catalyst for the reaction. Second step was carried out using hydrogen peroxide instead of benzyl peroxide as suggested in reported literature.

In this paper, Poly (n-acrylate-co-n-butylmaleimide) were prepared and tribological studies has been done by four ball tester and high frequency reciprocating friction and wear tester. On addition of Poly (n-acrylate-co-n-butylmaleimide) in base stock, performance found to be improved.

\section{Experimental}

\subsection{Materials}

All chemicals were purchased from commercial sources and used as received, unless otherwise stated. Fatty alcohols (lauryl, myristyl, palmityl, staeryl) $99 \%$ pure were obtained as gift samples from M/s. Godrej Industries Ltd., Mumbai. $p$-TSA (AR grade), acrylic acid (AR grade), maleic anhydride (AR grade), hydrogen peroxide (AR grade), n-butyl amine and dry benzene (AR grade), toluene (AR grade) was procured from M/s. Thomas Bakers, Mumbai. Commercial base oils 150 N, 500 N were obtained as a gift sample from M/s Savita Chemicals Ltd., Mumbai.

\subsection{Synthesis of n-Alkyl acrylates}

The reaction was carried out in a $250 \mathrm{ml}$ three-necked flask equipped with magnetic stirrer, thermocouple and Dean and Stark apparatus attached with a condenser. The acrylic acid esters were synthesized by reacting equimolar quantities of acrylic acid and n-alkyl alcohols ( $\mathrm{n}=12,14$, $16,18,18: 1)$ using p-TSA (1\% by wt) as a catalyst. Reaction was carried out at $120^{\circ} \mathrm{C}$ using toluene as solvent and was monitored by acid value (AV). Water was separated azeotropically using Dean-Stark apparatus. Reaction was terminated after 6 hours with the addition of requisite quantity of $\mathrm{NaOH}$. Esters were purified, adding water until a $\mathrm{pH} 7$ was obtained and methanol \& toluene were used as solvents for crystallization ${ }^{7}$. Traces of moisture were removed under vacuum.

\subsection{Preparation of anhydride copolymers and Poly ( $\mathrm{n}$ - alkylacrylates-co-N-butylmaleimide)}

In a $100 \mathrm{ml}$ four-neck round flask fitted with a mechanical stirrer, a condenser, a temperature controller, and a nitrogen-controlled inlet valve, the n-alkyl acrylates and maleic anhydride were added in 1:1 mole ratio in dry benzene under nitrogen atmosphere using hydrogen peroxide as initiator $\left(1 \%\right.$ by wt) at $60-70^{\circ} \mathrm{C}$ with constant stirring. After completion of the reaction benzene was distilled off under reduce pressure by keeping it at $60^{\circ} \mathrm{C}$ under vacuum for 2-3 h. The copolymers were purified by precipitation in excess volume of methanol and the vacuum dried for $24 \mathrm{~h}$. The resultant copolymers were allowed to react with n-butyl amine in 1:1 molar ratio in presence of molecular sieves using toluene as a solvent for 8-10 $\mathrm{h}^{8}$. The reaction steps are as shown in (Scheme 1).

\subsection{Viscosity index}

Viscosity index determined by ASTM method D2270-04 (Standard Practice for Calculating Viscosity Index from Kinematic Viscosity at 40 and $100^{\circ} \mathrm{C}$ ). Viscosity was determined by measuring the time for a volume of liquid to flow under gravity through a calibrated glass capillary cannon fenske reverse flow viscometer.

Temperature controlled water bath was set on $40^{\circ} \mathrm{C}$ and equilibrated for $30 \mathrm{~min}$ before measuring the viscosity of samples (base oil + synthesized compounds). Viscometer containing requisite quantity of the sample was kept vertically in water bath for $~ 10$ min.

Suction was applied to adjust the head level of the test sample to a position in the capillary arm of the instrument about $7 \mathrm{~mm}$ above the first timing mark. The sample was allowed to flow freely under the action of gravitational force. Efflux time (seconds) was measured using stopwatch. The kinematic viscosity $(\eta)$ was calculated in centistocks (cSt with units $\mathrm{cm}^{2} / \mathrm{sec}$ ) by multiplying the efflux time in $\sec (\mathrm{t})$ by viscometer constant $(\mathrm{A})^{9)}$.

$$
\eta=\text { At. }
$$

The procedure was repeated to obtain the viscosity at $100^{\circ} \mathrm{C}$. By using these two viscosities (at $40^{\circ} \mathrm{C}$ and $100^{\circ} \mathrm{C}$ ) of each sample viscosity index (VI) was calculated.

\subsection{Pour point}

Pour point of synthesized alkyl co-polymer was detected 
STEP-1

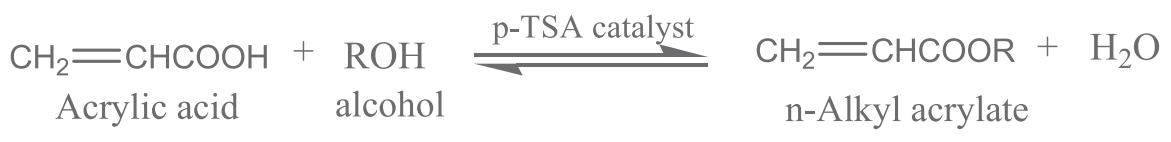

STEP-2

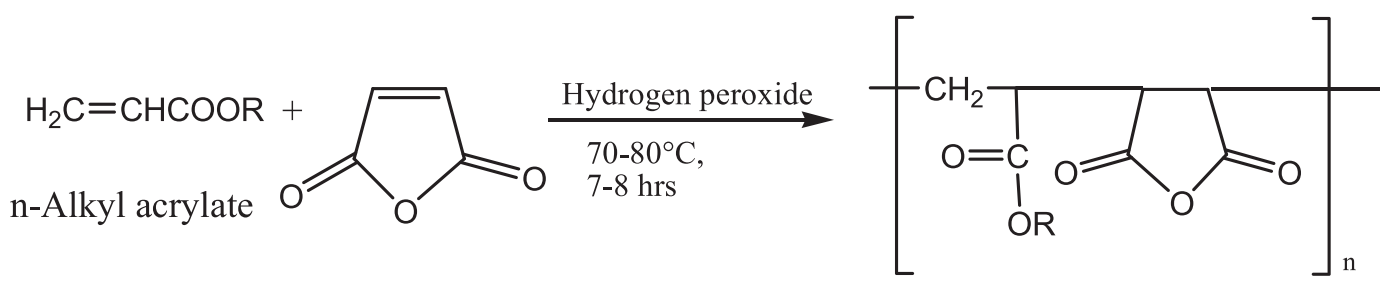

Maleic anhydride
Anhydride copolymer

\section{STEP-3 \\ $\underset{\mathrm{CH}_{3}\left(\mathrm{CH}_{2}\right)_{3} \mathrm{NH}_{2}}{\longrightarrow}$ $10-15 \mathrm{hrs}$, reflux}

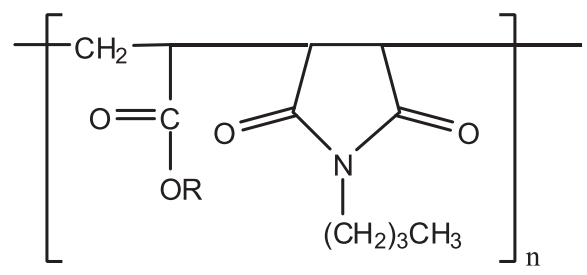

Poly(n-acrylate-co-n-butylmaleimide)

Anhydride coplymer

\begin{tabular}{cccc}
\hline Compound & $\begin{array}{c}\text { Molecular weight } \\
\text { of n-Alkyl } \\
\text { acrylates }\end{array}$ & $\begin{array}{c}\text { Molecular weight } \\
\text { of Anhydride } \\
\text { copolymers }\end{array}$ & $\begin{array}{c}\text { Molecular } \\
\text { weight of Poly } \\
\text { (n-alkylacrylates-co- } \\
\text { N-butylmaleimide) }\end{array}$ \\
\hline A1 & 240 & 338 & 361 \\
A2 & 268 & 366 & 389 \\
A3 & 296 & 394 & 417 \\
A4 & 324 & 422 & 445 \\
A5 & 322 & 420 & 443 \\
\hline
\end{tabular}

Scheme 1

by ASTM method D97-11 Standard Test Method. Pour point is the temperature at which the fluid is no longer flow able under the test conditions. Pour point measured manually by using apparatus Krisspair-hill thermal teknics PID2001. The sample (base oil + synthesized compound) placed in test tube with rubber cork and thermometer. This test tube was kept in pour point apparatus. Test tube was removed at the interval of three minutes and tilled to check the surface movement.

Pour point of synthesized alkyl co-polymer was detected by ASTM method D97-11 Standard Test Method.

\subsection{Wear scar and Weld load}

Wear scar and weld load characteristics were determined by ASTM D 4172 method using a four ball tester (Make: DUCOM; Model: TR-30L). The balls (AISI 52100 steel, 12.7 mm diameter, 64-66 Rc hardness and extreme polished) were thoroughly cleaned with n-hexane before each experiment. Pure base oil ( $150 \mathrm{~N}$ and $500 \mathrm{~N})$ and three different concentrations (1, 3 and $5 \mathrm{wt} \%$ ) of different synthesized Poly (n-alkylacrylates-co-N-butylmaleimide) (A1-A5) in pure base oil were tested. Test fluid $(15 \mathrm{~mL})$ was filled in the test cup to cover the stationary balls ${ }^{10}$. 
The weld load characteristics of the additives were evaluated on a four ball weld tester. The test consisted of a steel ball rotating under load on a set of three similar stationary balls under the fully submerged oil condition. The spindle was rotated at a speed of $1200 \mathrm{rpm}$. The load at which welding of balls occur is called as weld load. The weld load capacity was measured for all synthesized Poly (n-alkylacrylates-co-N-butylmaleimide).

The wear scar characteristics of the additives were evaluated on a four ball wear tester. In this test a steel ball reciprocates on a set of three similar steel balls under the fully submerged oil condition at a moderate load of $45 \mathrm{~kg}$ and a sliding velocity of $0.456 \mathrm{~m} / \mathrm{s}$ for duration of $1 \mathrm{hr}^{11)}$.

The oil temperature was maintained at $75^{\circ} \mathrm{C}$. The diameter of the scar produced on the steel balls was measured using a microscope. The wear scar diameter is a measure of antiwear characteristics of the synthesized Poly (n-alkylacrylates-co-N-butylmaleimide). The results are given as the means of three replicates \pm standard deviations.

\subsection{High frequency reciprocating friction and wear tester (HFRR)}

Boundary lubrication properties of synthesized Poly (nalkylacrylates-co-N-butylmaleimide) were studied using a ball-on-disk configuration on the instrument TR-282. In this test a steel ball oscillates under load on a steel disc. The friction force between two metal surfaces was measured by piezoelectric force transducers ${ }^{12)}$. The balls and the disks were thoroughly cleaned with fresh reagentgrade hexane prior to each experiment. The balls were made of AISI E-52100 steel(hardened: $62 \mathrm{HR}, \mathrm{Ra}<0.05$ mm, size: $6 \mathrm{~mm}$ diameter). Disc material was AISI E-52100 steel(hardness: $200 \mathrm{HV}$, annealed, Ra: $0.02 \mathrm{~mm}$, size: dia 10*4 $\mathrm{mm}$ wide). A total of 3-5 $\mathrm{mL}$ of the test fluid was poured in the cup to totally immerse the ball and disk. The duration of the friction test was $15 \mathrm{~min}$ at a sliding speed of 6.22 $\mathrm{mm} / \mathrm{s}(5 \mathrm{rpm})$ and normal load of $200 \mathrm{gm}$ at room temperature $^{13)}$. The temperature of the specimen and test fluid was $25^{\circ} \mathrm{C}\left(25^{\circ} \mathrm{C}\right.$, which increased by $\left.2-3^{\circ} \mathrm{C}\right)$ at the end of the test period. Friction and other data were recorded until the set time elapsed. The coefficient of friction was then calculated by measuring the friction force between two metal surfaces and the total force applied. The coefficient of friction is the ratio of friction force between two metal surfaces and the applied load. The coefficient of friction $(\mathrm{CoF})$ values reported are averages of three independent experiments with the standard deviation of 0.002 .

\section{Result and discussion}

In present research work prime objective was to synthesise polymers from fatty alcohol and acrylic acid and to study the effect on base oils $150 \mathrm{~N}$ and $500 \mathrm{~N}$. The empha- size was focused on various tribiological properties. The present study revealed the effect of synthetic additives on viscosity, pour point, load carrying properties, antiwear properties and friction performance. All results were also compared with industrial product K-26.

\subsection{Viscosity index}

Viscosity index (Figs. 1 and 2) was improved (Figs. 1 and 2) after addition of additive Poly (n-acrylate-co-nbutylmaleimide). VI found to be 155.71 and 166.74 respectively for base stock $150 \mathrm{~N}$ and $500 \mathrm{~N}$ and increased with chain length and decreased with unsaturation. Solubility of these polymeric additives was limited at lower temperature and increased with temperature. This was responsible for increased viscosity index for the base oils containing synthesized additive. These results were compared with industrial product K-26, which was found to be in accordance with A4.

\subsection{Pour point}

Pour point was lowered after addition of additive Poly (nacrylate-co-nbutylmaleimide). It was $-26^{\circ} \mathrm{C}$ and $-22^{\circ} \mathrm{C}$

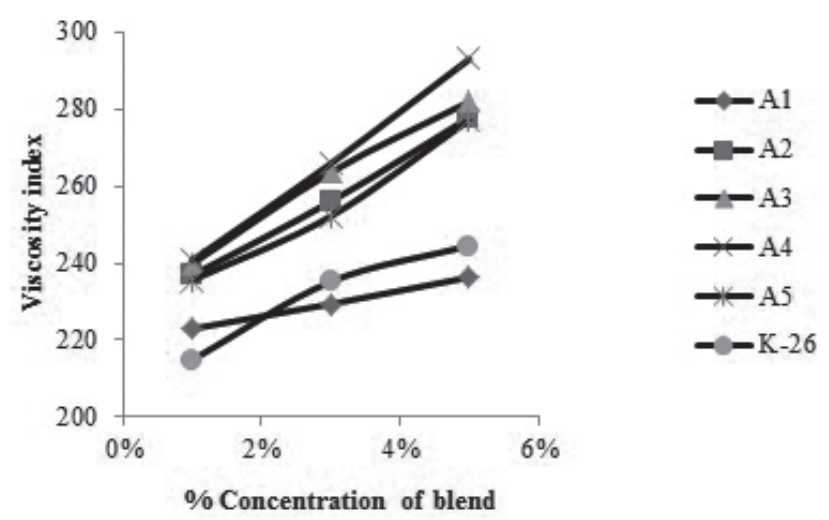

Fig. 1 VI against concentration of blend with $150 \mathrm{~N}$ base stock.

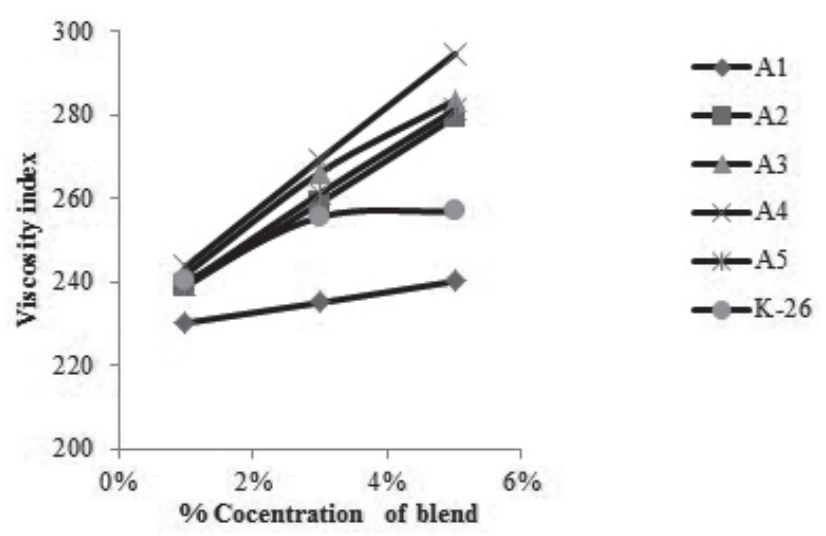

Fig. 2 VI against concentration of blend with $500 \mathrm{~N}$ base stock. 
Table 1 Wear scar and weld load of Poly (n-acrylate-co-n-butylmaleimide) with $1 \%, 3 \%, 5 \%$ blend in $500 \mathrm{~N}$ and $150 \mathrm{~N}$ base stock.

\begin{tabular}{|c|c|c|c|c|c|c|}
\hline \multirow{2}{*}{ Sr. No. } & \multirow{2}{*}{$\begin{array}{l}\text { Alkyl co- } \\
\text { polymer }\end{array}$} & \multirow{2}{*}{ Blend } & \multirow{2}{*}{$\begin{array}{l}\text { Wear scar } \\
(\mathrm{mm}) 500 \mathrm{~N}\end{array}$} & \multirow{2}{*}{$\begin{array}{l}\text { Wear scar } \\
(\mathrm{mm}) 150 \mathrm{~N}\end{array}$} & \multicolumn{2}{|c|}{ Weld load (Kg) } \\
\hline & & & & & in $500 \mathrm{~N}$ & in $150 \mathrm{~N}$ \\
\hline \multirow{3}{*}{1} & \multirow{3}{*}{ A1 } & $1 \%$ & $0.65 \pm 0.01$ & $0.70 \pm 0.01$ & 135 & 120 \\
\hline & & $3 \%$ & $0.60 \pm 0.01$ & $0.66 \pm 0.02$ & 150 & 135 \\
\hline & & $5 \%$ & $0.55 \pm 0.01$ & $0.61 \pm 0.01$ & 165 & 150 \\
\hline \multirow{3}{*}{2} & \multirow{3}{*}{$\mathrm{A} 2$} & $1 \%$ & $0.62 \pm 0.02$ & $0.68 \pm 0.01$ & 150 & 135 \\
\hline & & $3 \%$ & $0.56 \pm 0.02$ & $0.62 \pm 0.02$ & 165 & 150 \\
\hline & & $5 \%$ & $0.52 \pm 0.01$ & $0.58 \pm 0.01$ & 180 & 180 \\
\hline \multirow{3}{*}{3} & \multirow{3}{*}{ A3 } & $1 \%$ & $0.55 \pm 0.02$ & $0.64 \pm 0.01$ & 165 & 150 \\
\hline & & $3 \%$ & $0.49 \pm 0.02$ & $0.60 \pm 0.01$ & 180 & 165 \\
\hline & & $5 \%$ & $0.44 \pm 0.01$ & $0.55 \pm 0.01$ & 195 & 195 \\
\hline \multirow{3}{*}{4} & \multirow{3}{*}{ A4 } & $1 \%$ & $0.52 \pm 0.01$ & $0.62 \pm 0.02$ & 180 & 165 \\
\hline & & $3 \%$ & $0.47 \pm 0.01$ & $0.57 \pm 0.02$ & 195 & 180 \\
\hline & & $5 \%$ & $0.42 \pm 0.02$ & $0.52 \pm 0.01$ & 210 & 195 \\
\hline \multirow{3}{*}{5} & \multirow{3}{*}{ A5 } & $1 \%$ & $0.59 \pm 0.02$ & $0.67 \pm 0.02$ & 165 & 150 \\
\hline & & $3 \%$ & $0.55 \pm 0.01$ & $0.62 \pm 0.01$ & 180 & 165 \\
\hline & & $5 \%$ & $0.50 \pm 0.01$ & $0.56 \pm 0.01$ & 195 & 180 \\
\hline \multirow{3}{*}{6} & \multirow{3}{*}{$\mathrm{K}-26$} & $1 \%$ & $0.54 \pm 0.02$ & $0.57 \pm 0.02$ & 180 & 165 \\
\hline & & $3 \%$ & $0.49 \pm 0.02$ & $0.58 \pm 0.02$ & 195 & 180 \\
\hline & & $5 \%$ & $0.44 \pm 0.01$ & $0.53 \pm 0.01$ & 210 & 195 \\
\hline
\end{tabular}

for conventional diesel base stock $150 \mathrm{~N}$ and $500 \mathrm{~N}$ base stock respectively (Tables 2 and 3 ). Pour point decreases upto $1 \mathrm{wt} \%$ concentration for increased chain length. The lowest pour point was achieved at $1 \%$ additive concentration and still lowered with unsaturation. At higher concentration $(>1 \%)$ the additive itself acted as nucleating site that increased the pour point ${ }^{11)}$ (Table 2).

\subsection{Load-carrying property}

In order to investigate the effect of poly (n-acrylate-co-nbutylmaleimide) additive in lubricating oils, experiment were carried out using four ball machine. Weld load of plane base stock of $500 \mathrm{~N}$ was $195 \mathrm{Kg}$ and that of $150 \mathrm{~N}$ was $165 \mathrm{Kg}$. The weld load capacity of base stock blend were given in Table 3. The weld load capacity of base oils $(150 \mathrm{~N}$ and $500 \mathrm{~N})$ increased with an addition of poly (n-acrylate-co-n-butylmaleimide). The weld load capacity was observed higher for all the base stock blends (base oil + poly (n-acrylate-co-n-butylmaleimide)) as compared to base oils. The weld load capacity increases with increase in concentration of synthesized additive for all the poly (n-acrylate-co-n-butylmaleimide) studied.

These additive form layers on the metal surface by adsorption or chemisorptions, that guarantees their immediate availability in the case of mixed friction conditions. When hydrodynamic lubricating film is not present, extreme pressure (EP) additive can react with the metal surface forming tribochemical reaction layers that will prevent direct contact between the sliding metals.

Layers formed by only physically adsorbed polar substances Poly (n-acrylate-co-n-butylmaleimide), which exhibit moderate high pressure properties. EP additives are much more reactive and used when the stress of the system is very high in order to prevent the welding of the moving parts that otherwise would lead to severe damage $^{11)}$.

\subsection{Antiwear properties}

Table 1 showed variation in wear scar $(\mathrm{mm})$ with percent concentration of different poly (nacrylate-co-n-butylmaleimide). Wear scar diameter is an indication of extent of wear when sliding contact occurs. Wear scar of plan base stock $150 \mathrm{~N}$ found to be $0.68 \mathrm{~mm}$ and of $500 \mathrm{~N} 0.62 \mathrm{~mm}$ listed in Table 3. On addition additive Poly (n-acrylate-con-butylmaleimide) wear scar diameter decreases. The addition of poly (n-acrylate-co-n-butylmaleimide) possesses wear prevention characteristics to the base oils (lubricants).

Wear scar diameter decreased with an increase in chain length and increases with an increase in unsaturation listed in Table 1. During the tribochemical process, these molecules undergo chemical transformation at the metal 
Table 2 Pour point of Poly (n-acrylate-co-n-butylmaleimide) with $1 \%, 3 \%, 5 \%$ blend in 500 $\mathrm{N}$ and $150 \mathrm{~N}$ base stock.

\begin{tabular}{|c|c|c|c|c|}
\hline \multirow{2}{*}{ Sr. No. } & \multirow{2}{*}{$\begin{array}{l}\text { Alkyl co- } \\
\text { polymer }\end{array}$} & \multirow{2}{*}{ Blend } & \multicolumn{2}{|c|}{ Pour point $\left({ }^{\circ} \mathrm{C}\right)$} \\
\hline & & & $500 \mathrm{~N}$ & $150 \mathrm{~N}$ \\
\hline \multirow{3}{*}{1} & \multirow{3}{*}{$\begin{array}{c}\text { C12 } \\
\text { copolymer }\end{array}$} & $1 \%$ & $-32 \pm 2$ & $-30 \pm 2$ \\
\hline & & $3 \%$ & $-21 \pm 2$ & $-16 \pm 2$ \\
\hline & & $5 \%$ & $-8 \pm 2$ & $0 \pm 2$ \\
\hline \multirow{3}{*}{2} & \multirow{3}{*}{$\begin{array}{c}\text { C14 } \\
\text { copolymer }\end{array}$} & $1 \%$ & $-30 \pm 2$ & $-28 \pm 2$ \\
\hline & & $3 \%$ & $-19 \pm 2$ & $-14 \pm 2$ \\
\hline & & $5 \%$ & $-7 \pm 2$ & $4 \pm 2$ \\
\hline \multirow{3}{*}{3} & \multirow{3}{*}{$\begin{array}{c}\text { C16 } \\
\text { copolymer }\end{array}$} & $1 \%$ & $-28 \pm 2$ & $-26 \pm 2$ \\
\hline & & $3 \%$ & $-15 \pm 2$ & $-11 \pm 2$ \\
\hline & & $5 \%$ & $-5 \pm 1$ & $7 \pm 1$ \\
\hline \multirow{3}{*}{4} & \multirow{3}{*}{$\begin{array}{c}\text { C18 } \\
\text { copolymer }\end{array}$} & $1 \%$ & $-27 \pm 2$ & $-23 \pm 2$ \\
\hline & & $3 \%$ & $-13 \pm 1$ & $-9 \pm 1$ \\
\hline & & $5 \%$ & $-3 \pm 1$ & $8 \pm 1$ \\
\hline \multirow{3}{*}{5} & \multirow{3}{*}{$\begin{array}{c}\text { C18:1 } \\
\text { copolymer }\end{array}$} & $1 \%$ & $-29 \pm 2$ & $-27 \pm 2$ \\
\hline & & $3 \%$ & $-18 \pm 1$ & $-15 \pm 1$ \\
\hline & & $5 \%$ & $-7 \pm 1$ & $5 \pm 1$ \\
\hline \multirow{3}{*}{6} & \multirow{3}{*}{ K-26 } & $1 \%$ & $-26 \pm 2$ & $-22 \pm 2$ \\
\hline & & $3 \%$ & $-13 \pm 1$ & $-10 \pm 1$ \\
\hline & & $5 \%$ & $-2 \pm 1$ & $9 \pm 1$ \\
\hline
\end{tabular}

Table 3 Physicochemical properties of $500 \mathrm{~N}$ and $150 \mathrm{~N}$ base stock.

\begin{tabular}{ccc}
\hline Base stock & $150 \mathrm{~N}$ & $500 \mathrm{~N}$ \\
\hline Wear scar $(\mu \mathrm{m})$ & $0.68 \pm 0.012$ & $0.62 \pm 0.013$ \\
Weld load $(\mathrm{Kg})$ & 165 & 195 \\
Coefficient of friction $(\mathrm{mm})$ & $0.13 \pm 0.01$ & $0.11 \pm 0.01$ \\
Flash point $\left({ }^{\circ} \mathrm{C}\right)$ & $320 \pm 2$ & $356 \pm 2$ \\
Pour point $\left({ }^{\circ} \mathrm{C}\right)$ & $-26^{\circ} \mathrm{C} \pm 2$ & $-22^{\circ} \mathrm{C} \pm 2$ \\
Viscosity at $40^{\circ} \mathrm{C}$ & $17.99 \pm 0.01$ & $69.68 \pm 0.01$ \\
Viscosity at $100^{\circ} \mathrm{C}$ & $4.36 \pm 0.01$ & $11.84 \pm 0.01$ \\
Viscosity index & $155.71 \pm 2$ & $166.74 \pm 2$ \\
\hline
\end{tabular}

contact zone and develop a stable tribochemical film to protect further wear of the metal. These compounds demonstrate excellent antifriction and antiwear properties using four ball test. The thermal stability increases with the chain length of the alkyl groups, so the weld load capacity found to be more.

\subsection{Friction performance}

The coefficient of friction is maximum force that must be overcome to initiate macroscopic motion between two

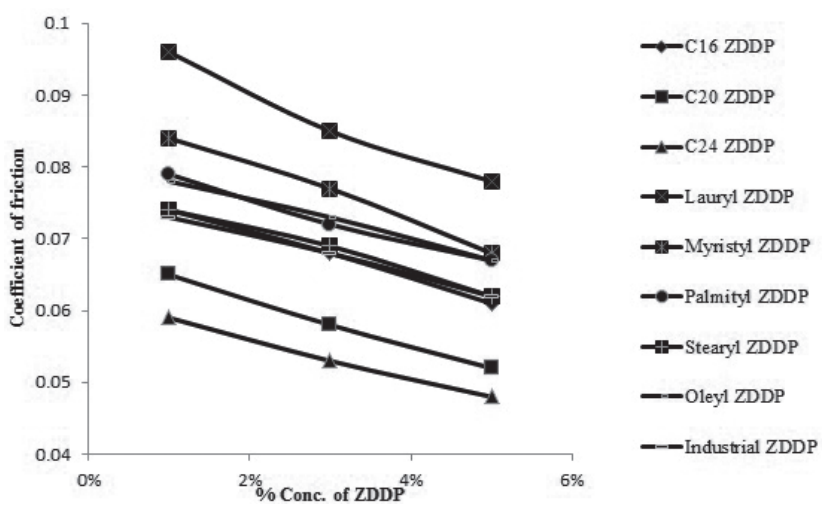

Fig. 3 Coefficient of friction against concentration of blend with $150 \mathrm{~N}$ base stock.

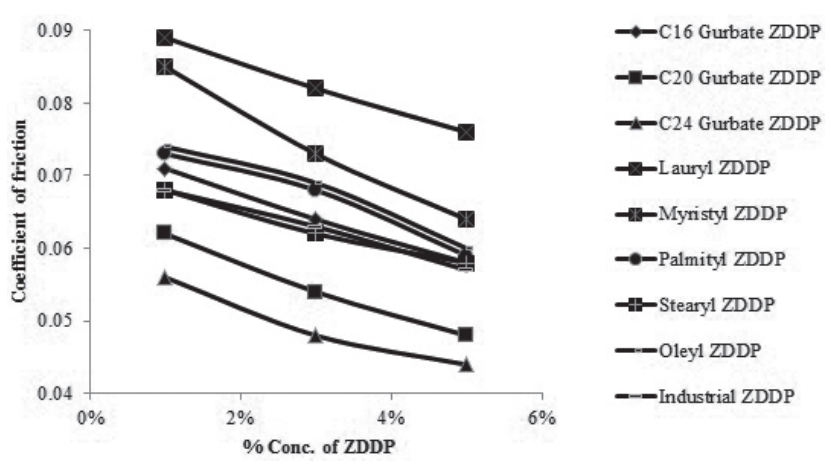

Fig. 4 Coefficient of friction against concentration of blend with $500 \mathrm{~N}$ base stock.

bodies. Additives, in combination with conventional diesel base stock $150 \mathrm{~N}$ and $500 \mathrm{~N}$ lowered the coefficient of friction to 0.13 and 0.11 (Table 2) respectively due to their polar characteristics ${ }^{6}$. The relationship between the concentration of the additive in plane base stock and the friction coefficient is shown in Figs. 3 and 4. It indicated that the friction coefficient of the additive was lowered at increased additive concentration upto $3 \mathrm{wt} \%$. Insignificant reduction in coefficient was observed beyond $3 \mathrm{wt} \%$.

\subsection{Compatibility/efficiency with industrial product K-26}

These results were compared with industrial product K-26, which was observed similar to A4 compound. All results were comparable with K-26. Pour point data reveals that as the alkyl chain length in PPD increases its efficiency as flow improver increases this may be due to effect of molecular weight. Table 1 shows same results in case of AW and EP property.

\section{Conclusion}

The synthesized poly (n-acrylate-co-n-butylmaleimide) showed good viscosity index improvers, EP and AW prop- 
erty. The addition of poly (n-acrylate-co-n-butylmaleimide) to the base oil improved the weld load capacity of base oil. Additive performance improved with increase in molecular weight and concentration of additive [poly (n-acrylate-co-nbutylmaleimide) ]. Presence of unsaturation affected the performance of additive. Synthesised Poly (n-acrylate-co-nbutylmaleimide) were good PPD's upto 1 wt\% concentration. Further increase in concentration adversely affected the pour point. Polymers A1-A5 found to be compatible with industrial product K-26. Results of A4 were observed similar to K-26.

\section{Reference}

1) Miskolczi, N.; Sagi, R.; Bartha, L.; Forcek, L. Utilization of $\alpha$-olefins obtained by pyrolysis of waste high density polyethylene to synthesize $\alpha$-olefin-succinic-anhydride based cold flow improvers. J Fuel Chem Technol. 37, 302-310 (2009).

2) Srivastava, S. P.; Tandon, R. S.; Verma, P. S.; Saxena, A. K.; Joshi, G. C.; Phatak, S. D. Crystallization behavior of n-paraffins in Bombay-High middle-distribution wax/gel. Fuel. 71, 533-537(1992).

3) Zhang, F. S.; Wang, B. Studies on the mechanisms involved in pour point depressant and viscosity deduction by some pour point depressants/viscosity reducers. Oilfield Chem. 12, 347-352(1995).

4) Coutinho, J. A. P.; Mirante, F.; Ribeiro, J. C.; Sansot, J. M.; Daridon, J. L. Cloud and pour points in fuel blends. Fuel. 81, 963-967(2002).

5) Chen, W.; Zhao, Z.; Yin, C. The interaction of waxes with pour point depressants. Fuel. 89, 1127-1132 (2010).
6) Huang, W.; Tan, Y.; Dong, J.; Chen, B. Tribological properties of the film formed by borated dioctyldithiocarbamate as an additive in liquid paraffin. Tribol Int. 35, 787-791 (2002).

7) Purification of laboratory chemicals, $5^{\text {th }}$ edition By W. L. F. Armarego, Christina Li Lin Chai.

8) Deshmukh, S.; Bharambe, D. P. Synthesis of polymeric pour point depressants for Nada crude oil (Gujarat, India) and its impact on oil rheology. Fuel processing Technology. 89, 227-233(2008).

9) Renner-Nantz, J. Food Analytical Chemistry (2001).

10) Tomala, A.; Naveira-Suarez, A.; Gebeshuber, I. C.; Pasaribu, R. Effect of base oil polarity on micro and nanofriction behavior of base oil + ZDDP solutions. Tribology. 3, 182-188(2009).

11) Tuszynski, W.; Molenda, J.; Makowska, M. Tribochemical conversions of zinc dialkyldithiophosphate (ZDDP) under extremely different pressure conditions. TriboLett. 13, 103-109 (2002).

12) McQueen, J. S.; Gao, H.; Black, E. D.; Gangopadhyay, A. K.; Jensen, R. K. Friction and wear of tribofilms formed by zinc dialkyldithiophosphate antiwear additive in low viscosity engine oils. Tribol Int. 38, 289297 (2005).

13) Erhan, S. Z.; Sharma, B. K.; Lui, Z.; Adhvaryu, A. Lubricant Base Stock Potential of Chemically Modified Vegetable Oils. J Agric Food Chem. 56, 8919-8925 (2008).

\section{Acknowledgement}

Authors are thankful to by University Grant Commission (UGC), Government of India for financial assistance. 